\title{
La Prensa en la Segunda República: breve aproximación como contexto vital de don Diego Martínez Barrio
}

\author{
Rafael Guerrero Moreno
}

Periodista

\section{RESUMEN}

La Segunda República fue un corto pero apasionante periodo de tiempo, de alto pluralismo y fuertes oscilaciones en el poder. Esa actividad febril se trasladó a la Prensa, que vivió la aparición y la desaparición de cientos de periódicos dispersos por toda España. He aquí una visión de esos años.

\section{ABSTRACT}

The Second Republic was a short but exciting period of time, of high pluralism and strong oscillations in the power. This feverish activity moved to the Press, which lived through the appearance and the disappearance of hundreds of newspapers, dispersed for the whole Spain.

Palabras claves: Segunda República/Prensa/España/Partidos Políticos.

Key Words: Second Republic/Press/Spain/Political Parties.

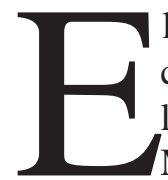

1 objetivo de este trabajo es tratar de rescatar del olvido y de dar cumplimiento a la última voluntad del único ciudadano sevillano que ha llegado a ostentar la más alta magistratura del Estado Español, Diego Martínez Barrio, cuyos restos ya reposan donde él quiso siempre: en el cementerio hispalense de San Fernando.

Cuando decidí realizar este estudio pensé que mi condición de periodista me obligaba a hablar sobre la prensa en la Segunda República, centrándome especialmente en Andalucía, pero la selección del tema también se justifica en este marco In Memoriam, considerando además el perfil profesional de don Diego que, además de tipógrafo de oficio, compaginó su dedicación política a la condición circunstancial de promotor y editor de periódicos y semanarios de doctrina política radical. Sin mucha fortuna, por cierto, en estos empeños. 
La Segunda República Española fue un periodo movido y cambiante en lo político y social, pero también en los medios de comunicación. Cuando hablamos de medios de entonces lo hacemos refiriendonos a la Prensa, porque la radio estaba en pañales y la televisión no existía.

La Segunda República fue un corto pero apasionante periodo de tiempo, de alto pluralismo y sopa de letras de partidos y fuertes oscilaciones en el poder. Esa actividad febril se trasladó a la Prensa, que vivió la aparición y la desaparición de cientos de periódicos dispersos por toda España, de la más variopinta ideología. Y todo, bajo el denominador común de una intensa politización. Pese a la multiplicación de periódicos, la mayoría eran de corta vida y excesivamente politizados en el sentido de la dependencia directa de un partido. Los grandes periódicos de empresa (más profesionales e independientes, aunque tuvieran su ideología) cobraron peso frente a la prensa de partido. Surgieron muchas cabeceras obreras, pero sin difusión real. Y la mayor parte de los grandes rotativos de empresa no fueron precisamente condescendientes con el nuevo régimen. Su estrategia osciló desde la tibieza a la manifiesta hostilidad ${ }^{1}$.

¿Qué tipo de periodismo demandaba el lector de Prensa en la República? Si ahora, en el umbral del siglo XXI impera el periodismo informativo e interpretativo, entonces imperaba el de opinión, pero no una opinión cualquiera, sino una opinión beligerante, apasionada y de batalla. No era más que el reflejo de la polarización social, y la Prensa la alimentaba.

Las vísperas republicanas, meses antes de las elecciones municipales de 1931, fueron especialmente febriles en cuanto a la creación de periódicos, lo que proporcionó al sector un impulso y una vitalidad desconocidos, después de que la prensa hubiese padecido un serio retroceso durante la Dictadura de Primo de Rivera.

Otros efectos de la proclamación de la República fueron poner freno al proceso de concentración de medios iniciado en los años $20 \mathrm{y}$, sobretodo, y pese a las dificultades económicas, elevar la difusión de la prensa con tiradas importantes que tardarían décadas en superarse. Este hecho resulta muy significativo, porque la República elevó el interés ciudadano por la información -y ya se sabe el dicho de que la información nos hace libres- y eso se tradujo en un desconocido aumento del nivel de lectura. Pero luego llegaría la ausencia de libertad, el oscurantismo franquista, la apatía y el desinterés, cuyos efectos culturales todavía padecemos siendo hoy España el furgón de cola de Europa en cuanto a lectura de prensa.

1 Antonio Checa Godoy, Historia de la prensa andaluza, Fundación Blas Infante, Sevilla, 1991. 
Pocas semanas antes de la proclamación de la República, Ortega y Gasset publicaba en $\mathrm{El} \mathrm{Sol}$ un artículo en el que dejaba constancia de la creciente influencia de la Prensa, vaticinando así el proceso hacia una sociedad mediática como la que ahora vivimos. "Hoy no existe en la vida pública más poder espiritual que la Prensa", decía Ortega, que añadía a continuación: "A estas fechas han desaparecido los antiguos poderes espirituales: la Iglesia, porque ha abandonado el presente y la vida pública es actualísima; el Estado, porque triunfante la democracia, no dirige ya a ésta, sino al revés, es gobernado por la opinión pública. En tal situación, la vida pública se ha entregado a la actualidad: la prensa"².

Uno de los aspectos más curiosos de la etapa republicana en relación a la prensa, fue la fuerte interrelación entre periodistas y políticos. Nada menos que 47 periodistas fueron diputados en las Cortes Constituyentes de 1931. Era la tercera profesión, después de catedráticos y de abogados. Y en los Gobiernos también había periodistas: la mayoría de los ministros del primer Gobierno republicano había dirigido algún periódico (como Alejandro Lerroux y Marcelino Domingo) y casi todos habían sido asiduos colaboradores en prensa.

Política y periodismo estaban estrechamente vinculados, para lo bueno y para lo malo. Porque también hay que decir que fueron masivas las suspendiones de periódicos en 1932 y, especialmente, en 1934. Las frecuentes convocatorias electorales animaban el cotarro periodístico y era común que se montaran periódicos que nacían para apoyar a partidos en la campaña y que después desaparecían. No había el más mínimo recato a la hora de pronunciarse a favor de una organización política ${ }^{3}$.

Ahora todo es mucho más sutíl, e incluso parecen haberse cambiado las tornas, ya que son los medios los que influyen de forma creciente sobre los políticos. De hecho, hoy son cada vez más los teóricos de la comunicación que están convencidos de que los medios ya no son el Cuarto Poder, sino el primero, con lo que el esquema clásico de la división de poderes de Montesquieu habría quedado prácticamente en pura teoría. Y si no, reflexionen sobre tantos ejemplos de sugerencias de calado que parten de los medios y que son asumidas rápidamente por los partidos. Es la sociedad mediática, con sus perversiones y sus virtudes, porque no me negarán que la influencia mediática ha podido ser decisiva ahora para hacer justicia y saldar la deuda histórica con la figura de Martínez Barrio.

Pero volvamos a la República, donde la simbiosis prensa-poder fue tal que muchos periodistas que promovieron periódicos ideológicos acaban dedicándose a

2 Vid. Manuel Tuñón de Lara (dir.), La prensa de los siglos XIX y XX, Servicio Editorial Universidad del Pais Vasco, Bilbao, 1986.

3 Vid. María Cruz Seoane y María Dolores Sáiz, Historia del Periodismo en España, 3, Alianza, Madrid, 1996. 
la politica, o compaginando ambas actividades. Montaban un periódico o se aprovechaban de su influencia para acabar en el Congreso de los Diputados.

Hay bastantes ejemplos que ilustran aquella realidad, como: de la CEDA

- José Moreno Dávila, impulsor de Ideal de Granada, redactor y diputado CEDA.

- Jesús Pabón, director de El Correo de Andalucía, diputado también de la

- Eloy Vaquero, ministro de Lerroux y propietario de $L a$ Voz de Córdoba

- Dionisio Cano, dirigente del Partido Republicano conservador y creador de "Odiel" en Huelva

- Domingo Tejera, director de La Unión, diario integrista católico de Sevilla, que en 1933 logra un escaño

- Juan José Palomino, de las bodegas Palomino y Vergara, dueño del Diario de Jerez, que también consigue ser diputado en el 33.

- León Carlos Alvarez, que crea La Mañana de Jaén, un diario conservador agrarista, desde el que se catapulta a la Dirección General de Agricultura.

Seguro que, dada su vocación política, ninguno de ellos se planteaba el difícil equilibrio que ahora se exige a un profesional del periodismo a la hora de establecer la relación con los políticos. Una relación que es saludable y peligrosa a la vez. Una historia de amor y odio, que precisa de confidencias, pero que no debe caer en condicionamientos que menoscaben la independencia profesional. Unas reglas del juego complicadas y basadas en aquello de "Ni contigo, ni sin tí". Estos periodistas metidos a políticos no tenían esos problemas de conciencia. Aunaban en sí mismos una contradicción que no les preocupaba, pero que tampoco le reprochaban desde fuera.

Pero no son sólo los periodistas quienes se meten a políticos dentro del sector prensa. Ruiz Alonso era tipógrafo en el diario católico Ideal de Granada y consiguió acta de diputado en 1936. Le llamaban el "obrero amaestrado" y su nombre arrastra la mala fama de haber sido el que delató a los falangistas que García Lorca estaba en casa de Luis Rosales.

Martínez Barrio, desde una posición política bien distinta, también fue un tipógrafo que hizo carrera política y que, además, aprovechó sus conocimientos técnicos y su intuición para promover periódicos de obediencia radical por toda Andalucía.

"Toda persona tiene derecho a emitir libremente sus ideas y opiniones, valiéndose de cualquier medio de difusión, sin sujetarse a previa censura. En ningún caso podrá recogerse la edición de libros o periódicos, sino en virtud del mandamiento judicial competente. No podrá decretarse la suspensión de ningún periódico, sino por sentencia firme". Esto decía el artículo 34 de la Constitución 
republicana aprobada en diciembre de 1931, referido a la Libertad de Prensa. Esa era la cara de las libertades republicanas ${ }^{4}$.

Pero también estaba la cruz, ya que la Ley de Defensa de la República, vigente aún por tiempo limitado, mantenía medidas restrictivas al prohibir la difusión de noticias que pudieran "quebrantar el crédito o perturbar la paz o el orden público", así como informaciones que menospreciaran a la República e hiciesen apología de la monarquía. (Ahora sólo se persigue la apología del terrorismo, lo que llevó a la cárcel durante varios meses a la Mesa Nacional de HB) Y esa ley contradictoria con la Constitución establecía penas desde el confinamiento o extrañamiento, multas de hasta 10.000 pesetas, y hasta el cierre de la publicación.

Con ese panorama, diarios como $A b c$, monárquico, o El Debate, católico, sufrieron los efectos represivos de la ley, de la que también fueron víctimas en Andalucía los diarios tradicionalistas El Correo de Andalucía de Sevilla, El Cronista de Málaga, El pueblo católico de Jaén y La Información de Cádiz. Estos periódicos fueron suspendidos temporalmente tras la Sanjurjada en agosto del 32, pero reaparecieron después.

La prensa de derechas contaba con una ventaja importante y sustancial sobre la de izquierdas: tenía solidez y respaldo económicos. Los terratenientes y aristócratas financiaban a los medios hipercríticos con la República y no dudaban en inventar una nueva cabecera cuando la anterior había quedado amortizada. Y también utilizaban a periodistas-políticos para que montaran infraestructura interprovincial. Es el caso de Domingo Tejera, que además del periódico integrista La Unión de Sevilla, llegó a dirigir simultáneamente también Diario de Jerez y La Información de Cádiz.

(Hay, por ciento, una anécdota del sevillano Domingo Tejera en relación con Martínez Barrio. Días después de la sublevación, Queipo de Llano que semanas antes iba tras Martínez Barrio adulandole y pidiendole favores, escribió en La Unión un artículo acusando a Don diego de ser "hijo natural, ladrón y marica". Tal fue el grado de insultos chabacanos vertidos en las páginas sin conocimiento del director que Domingo Tejera tuvo que dar explicaciones a sus lectores al día siguiente. Aunque suponemos que las disculpas serían tibias).

Al vencer la vigencia de la polémica Ley de Defensa de la República en agosto del 33, el Gobierno Azaña la sustituyó rápidamente por la Ley de Orden Público. De nuevo en contradicción con el espíritu garante de las libertades de la Constitución del 31, esta norma sería el nuevo instrumento represor contra la prensa, que fue profusamente empleado por los gobiernos derechistas: decenas de periódicos y semanarios progresistas fueron cerrados y bastantes periodistas fueron

4 Vid. Antonio Checa Godoy, op. cit. 
encarcelados. Un ejemplo en Andalucía fue el cierre del diario azañista almeriense Lucha y el ingreso en prisión del director y de los redactores del periódico.

En efecto, durante el segundo bienio republicano, la libertad de expresión se vió más constreñida que en el primero. La censura previa era lo habitual gracias a la Ley de Orden Público, especialmente tras la Revolución de Octubre de 1934. A partir de entonces numerosos periódicos obreros y republicanos de izquierda sufrieron largas suspensiones y cierres.

Era la venganza de quienes estaban convencidos de que la prensa había sido en buena medida culpable de la llegada de la República, lo que por otra parte constituye un temprano reconocimiento del hecho mediático en el primer tercio del siglo. Decía Gil Robles: "Esta revolución social, moral y jurídica la han hecho unos cuantos periódicos de izquierda" y Angel Herrera extendía la responsabilidad a otros ámbitos: "La prensa que, junto con las Casas del Pueblo, ha estado a las órdenes de la masonería, explica perfectamente los sucesos del año 1931".

La censura previa duró 15 meses, hasta las vísperas de la vistoria del Frente Popular en $1936 . .$. pero tras un breve periodo de libertad de prensa, y ante el clima social de violencia que presagiaba el desencadenamiento de la Guerra Civil, impuso la censura previa ${ }^{5}$.

Pero la derecha, siempre más ducha en virtudes o vicios mediáticos, burló la censura previa aprovechando un resquicio legal para extender sus discursos apocalípticos a la opinión pública. Como el único ámbito no sometido a censura era el parlamentario, los líderes derechistas utilizaron los debates parlamentarios no para dirigirse sólo a los escaños, sino más bien para hacerlo al país, conscientes de que su prensa afín ampliaría el eco de su retórica catastrofista fuera del hemiciclo. Los parlamentarios de ahora ponen especial énfasis en sus discursos no tanto por debatir en la Cámara, sino porque son conscientes del eco mediático a través de prensa, radio y televisión. Aunque también conviene advertir que, de alguna manera, los parlamentos han dejado de ser el escenario principal, el centro del debate político, algo que ahora está más en los medios de comunicación que, agrupados en holdings multimedia, se han convertido en los grandes grupos de presión.

Pero volvamos al pasado republicano para describir el panorama de la prensa andaluza de entonces. Pese a la politización del discurso periodístico o tal vez gracias a ello, que era lo que demandaba aquella sociedad convulsionada y polarizada, es el periodo histórico con más índice de lectura entre la población. El periódico de más tirada era El liberal de Sevilla, que era republicanista de izquierdas con unos 50.000 ejemplares; seguido de La Unión Mercantil independiente de Málaga con 30.000, y de $A B C$ de Sevilla, con unos 25.000.

5 Vid. Eloy Vaquero, El drama de Andalucía, Ayuntamiento de Córdoba, Córdoba, 1987. 
Ahora hay tiradas mayores en Andalucía, pero no mucho más. Y hay que considerar a la hora de comparar entre ayer y hoy, que entonces había mucha menos población y que el índice de analfabetismo era muy elevado. Había, además, periódicos que lanzaban varias ediciones diarias como Diario de Cádiz, El Defensor de Granada y $L a$ Voz de Córdoba ${ }^{6}$.

Tras una etapa de desconcierto y confusión inicial, la derecha se reorganiza mediáticamente en 1932 y con el apoyo de la CEDA lanza con éxito periódicos como Ideal en Granada que a poco de empreder su andadura se coloca en unos 8.000 ejemplares para competir frente a El Defensor, republicano de izquierdas. Y en otras provincias nacen Odiel de Huelva, Guión de Córdoba y Ayer en Jerez. En Sevilla, $A B C$ aguanta fiel a sus principios monárquicos y se consolida.

Tras el desmoronamiento del Partido Radical, la CEDA se convierte en el único referente político de la derecha y extiende su influencia mediática con periódicos en todas las provincias andaluzas. En vísperas de las elecciones de febrero del 36, se puede afirmar que la derecha controla informativamente Andalucía, pese a que Unión Republicana de Martínez Barrio e Izquierda Republicana siguen lanzando medios, pero estos son semanarios comarcales menores. Izquierda Republicana se apoya en rotativos veteranos como El Defensor de Granada, El Liberal de Sevilla, El Noticiero gaditano y Diario de Almería.

La prensa obrera en Andalucía se caracteriza por múltiples publicaciones para militantes, pero con escasa difusión. Los comunistas crean semanarios en Sevilla y Córdoba. La fuerza social del anarcosindicalismo en el campo y las ciudades andaluzas no se corresponde con la debilidad de sus medios: mientras que la prensa socialista vive su época dorada con diarios en Jaén, Córdoba, algeciras y Jerez, y con 20 semanarios comarcales. La prensa obrera se caracterizaba por su humilde impresión, pocas páginas, ausencia de publicidad y tan escasos recursos que no podía sobrevivir a las multas y a las suspensiones gubernativas.

En términos generales, la Prensa republicanista en Andalucía decrece a partir del 33 y cae en el 36. La pérdida del poder político y la endeblez financiera son los motivos. Por poner un ejemplo: Linares llegó a contar en 1931 con dos periódicos El Día y $L a$ Tarde. Tan sólo un año después, no quedaba ninguno.

En este repaso a la Prensa andaluza durante la República, falta la Prensa radical. Una Prensa que, teniendo en cuenta la memoria del hombre que ahora nos reúne, merece una consideración especial. Andalucía fue un buen granero de votos para el Partido Republicano Radical, como se refleja en el hecho de que 21 de los 93 diputados que tenía en 1931 eran andaluces. En 1933 son 25 los parlamentarios radicales andaluces del total de 104 obtenidos. Este importante peso específico se trasladó a la prensa, ya que el Partido Radical llegó a disfrutar en nuestra Comunidad

6 Vid. AA. VV., 50 años de Córdoba, Diputación Provincial, Córdoba, 1991. 
de una de sus redes más potentes de periódicos. Llegó a contar con diarios en cinco provincias (Almería, Córdoba, Granada, Málaga y Cádiz) sin mencionar el efímero El Pueblo que Martínez Barrio fundó en Sevilla. Y hubo semanarios radicales en otras 10 poblaciones. Cabeceras diarias como El Popular de Málaga, La Voz de Córdoba, La Publicidad de Granada, La República y La Voz de Almería son ejemplos de esa pujanza, aunque ninguno de ellos llegó a liderar el mercado.

La Prensa radical en Andalucía crece en 1930-31, recibe otro impulso en el 33, pero decae en el 35-36 conforme se hunde el partido que la promueve. En Sevilla, Diego Martínez Barrio decide probar suerte en la primavera del 31 y funda El Pueblo, pero fracasa a las pocas semanas. ¿Por qué el principal líder radical andaluz, conocedor del sector prensa, no logra su objetivo?. La respuesta es fácil y la da la propia dinámica del mercado periodístico. En Sevilla había dos periódicos fuertes que copaban el mercado: El Liberal, republicano de izquierdas que era una auténtica plataforma progresista, y $A b c$, monárquico conservador. Los diarios católicos conservadores El Correo y La Unión sobrevivían con una difusión menor y, sencillamente, no había hueco en el mercado para el experimento de Martínez Barrio que, con su fracaso editorial, demostró que periodísticamente no era profeta en su tierra, aunque si lo consiguiera politicamente. En 1934 Martínez Barrio, ya escindido del partido de Lerroux y con su nueva bandera política de Unión Republicana, volvió a intentarlo en Sevilla, pero sin correr tantos riesgos, y creó el semanario Renacer, aunque tampoco tuvo éxito, al igual que le ocurrió con la revista Democracia en Huelva, fundada ese mismo año ${ }^{7}$.

En términos cualitativos, donde más éxito alcanzó Martínez Barrio fue en Málaga, donde el editor de El Popular, el histórico dirigente radical Pedro Gómez Chaix puso a disposición de Unión Republicana su plataforma, que era el segundo periódico malagueño en difusión, y que se convirtió en el referente periodístico para la izquierda en esa provincia.

Si en sus pinitos como editor no consiguió sus objetivos, Diego Martínez Barrio sí que demostró sobradamente su influencia político-mediática, en 1934 tras su divorcio con Lerroux, al arrastrar hacia su nuevo proyecto político la red de medios radicales en Andalucía, una red que ya empezaba a decaer. Además de El Popular, también se pone a su servicio el semanario La República de La Línea, propiedad del masón y radical Adolfo Chacón. Conforme se polarizaba la sociedad, poco iba pintando en Andalucía la opción radical centrista de Lerroux, que se había desprestigiado al pactar con la derecha.

7 Vid. Manuel Alonso Rincón, El Correo de Andalucía, 100 años de Sevilla, Fomento de Iniciativas Andaluzas, S.A., Sevilla, 1999. 
A propósito del centro, permítanme una reflexión actual, ya que no deja de ser un referente aplicable por igual a la política y a la comunicación. En una sociedad democrática estable como la española, la inmensa mayoría de la población vota centro izquierda o centro derecha. Más del 80 por ciento de los diputados que integran el arco parlamentario español se mueven en esa órbita ideológica. La prensa, los medios de comunicación, saben que su público está ahí, y también se centran, escorándose a un lado o a otro, pero siempre en términos de centro. Pero en la convulsa etapa de la Segunda República se radicalizaron las posturas, se polarizó la sociedad.

Se supone que los radicales deberían haber ocupado esa posición centrista, pero fracasaron por su falta de organización y por sus divisiones internas. Conforme avanzó la República, la prensa se politizó adoptando, como los políticos, posiciones extremas, de elevada confrontación dialéctica. Y entonces el centro dejó de ser un referente adecuado para moverse. Se desprestigió, perdió fuelle y adeptos. Y su prensa también decayó en paralelo.

En 1934, en el contexto de la reorganización de los partidos republicanos de izquierda, que confluyen en Unión Republicana e Izquierda Republicana, sin excesivas diferencias ideológicas entre sí, cada uno intenta promover su prensa de partido con escasos recursos, pero sobretodo necesitan el concurso de periódicos republicanos independientes para llegar a la opinión pública. Ya a finales del 33, Manuel Azaña lanza un lamento mediático premonitorio: "Vivimos en la revolución, pero seguimos en la prensa de la monarquía". Azaña vislumbra ya que la pérdida progresiva de la batalla mediática acabaría trayendo males mayores... y así fue.

Sin embargo, ante la carencia o endeblez de órganos periodísticos propios o afines, hubo dos personajes en la República que fueron especialmente hábiles a la hora de influir entre la opinión pública. Lerroux y Azaña aprovecharon su ascendencia sobre los grandes periódicos republicanos independientes para defender sus criterios políticos sin cortapisas, una habilidad que fue más limitada en el caso de Martínez Barrio, de quien Alcalá Zamora elogia su "inteligencia natural e intuición", al tiempo que reconoce "sus deficiencias de estudio, preparación y experiencia".

A fin de cuentas y puestos a comparar en sabiduría y experiencia mediática, Martínez Barrio era tipógrafo, mientras que Lerroux era un periodista experimentado que había montado una red de cien periódicos en toda España, como El Progreso de Barcelona, que creó y dirigió. De hecho, con su larga trayectoria periodística a cuestas, Lerroux fue el típico ejemplo de periodista-político. Pero él mismo se descalifica en el plano humano cuando, tras haber colaborado tanto tiempo con Martínez Barrio, no encuentra más argumentos de reproche hacia el sevillano que acusarle de "no mirar de frente, de ser reconcentrado, escurridizo y frío". Desconozco si hubo entre ellos, además de desencuentro estratégico en el radicalismo, algún íntimo trasfondo de celos profesionales. Porque en aquellos 
viejos tiempos del sistema de impresión de periódicos en tipografía, había piques permanentes entre periodistas y personal de talleres. En mis primeros pinitos periodísticos hace más de 20 años, escuché a unos y a otros cómo se tiraban a matar, retóricamente hablando. Decían los linotipistas: "El mejor periodista, ahorcado" y contestaban los redactores: "Sí, pero con las tripas de un linotipista".

Bromas macabras aparte, no quiero cansarles más y quiero concluir señalando que la efervescencia que vivió el panorama periodístico andaluz durante la República tuvo como contrapunto primero la Guerra Civil y luego la oscura noche de los tiempos franquista. Los 34 periódicos que se editaban en Andalucía en 1936 quedaron reducidos a 15 al final de la contienda.

Algunos de los diarios antes mencionados fueron requisados y sus cabeceras cambiadas por denominaciones franquistas, como "Azul" o "Patria" para nutrir la Prensa del Movimiento. Otras instalaciones fueron asaltadas y quemadas. Y los periodistas huyeron de la quema como pudieron, aunque hubo otros que fueron directamente fusilados como Constantino Ruiz Carnero, director de El Defensor de Granada, y Pablo Troyano, director de La Voz de Córdoba.

Y hubo un tipógrafo honesto y comprometido con el difícil tiempo que le tocó vivir. Tras el Alzamiento, un periódico integrista pidió al Ayuntamiento de Sevilla que lo declarase "hijo maldito de Sevilla", cinco años después de haber recibido el nombramiento de "Hijo Ilustre y Predilecto de la Ciudad de Sevilla" que con tanto orgullo y nostalgia llevó hasta el día su muerte en el exilio parisino. Un hombre sobre el que afortunadamente ha dejado de pesar ya, como una maldición, la más injusta de las condenas: la del olvido.

\section{Bibliografía:}

- ALFONSO RINCÓN, Manuel: El Correo de Andalucía. 100 años de Sevilla. Fomento de Iniciativas Andaluzas SA, Sevilla, 1999.

- CHECA GODOY, Antonio: Historia de la Prensa andaluza. Fundación Blas Infante, Sevilla, 1991.

- CHECA GODOY, Antonio: Prensa y partidos políticos durante la II República. Ediciones Universidad de Salamanca, Salamanca, 1989.

- MARÍA CRUZ, Seoane y DOLORES SÁIZ, María: Historia del Periodismo en España 3. El siglo XX, 1898-1936. Alianza Universidad Textos. Madrid, 1996.

- RAMOS ESPEJO, Antonio: Después de Casas Viejas. Argos Vergara, Barcelona, 1984.

- RAMOS ESPEJO, Antonio: García Lorca en Córdoba. Diario Córdoba SA, Córdoba, 1998.

- SÁNCHEZ GARRIDO, J.L.; SOLANO MÁRQUEZ, F; FERNÁNDEZ Manuel; LUQUE, Rosa y GALÁN, Antonio. 50 años de Córdoba. Diputación Provincial de Córdoba, Córdoba, 1991. 
- TOBAJAS, Marcelino: El periodismo español. Ediciones Forja SA, Madrid, 1984

- TUÑÓN DE LARA, Manuel: La Prensa de los siglos XIX y XX. Servicio Editorial Universidad del País Vasco, Bilbao, 1986.

- VAQUERO, Eloy: El drama de Andalucía. Colección Díaz del Moral, Ayuntamiento de Córdoba, Córdoba, 1987.

- VIGUERAS, Francisco: Granada, 1936. Muerte de un periodista. Comares, Granada, 1998.

(Recibido el 10-6-2001, aceptado el 14-2-2002) 


\title{
Notas sobre psicoanálisis, literatura y comunicación. Algunas consideraciones a propósito del amor en la novela Cuaderno de viaje de Salvador Compán
}

\author{
Ramón Sarmiento
}

Psicoanalista,

Grupo de Investigación en Estructura, Historia y Contenidos de la Comunicación

\section{RESUMEN}

Partiendo de la lectura de la novela Cuaderno de viaje de Salvador Compán se hace un reflexión en torno al amor/eros, a partir de la cual se establecen algunos interrogantes y conjeturas.

Según las tesis psicoanalíticas, en especial las freudianas y lacanianas, toda relación humana supone un vínculo entre los sujetos implicados que queda regido por las leyes del inconsciente tal y como se manifiesta en la puesta en acto de la transferencia.

Aplicando estas tesis a la lectura de la novela hemos tratado de extraer una serie de consecuencias e interrogantes que puede no dejar de ser oportuna para una investigación psicoanalítica sobre el amor y en especial sobre el vínculo afectivo como factor inherente al proceso de comunicación.

\section{ABSTRACT}

Based on a reflection about love and eros from a review of Cuaderno de viaje, romance by Salvador Compán, some considerations and conjectures are done.

From a psychoanalytical perspective and especially from freudian and lacanian finding, human relationship includes a link between subjects that is ruled by the laws of unconscious as we can observe in the act of transference.

Results of the review of the romance from this theorethical perspective offer a support for some consecuences and hypothesis concerning a psychoanalytical research about eros, death, love and aggressive instincts, especially about affective link in comunication process.

Palabras claves: Psicoanálisis/Literatura/Comunicación/Salvador Compán/Cuaderno de Viaje.

Key Words: Psychoanalisis/Literature/Communication/Salvador Compán/Cuaderno de Viaje.

1 Versión escrita de la intervención, que tuvo lugar en Sevilla el 4 de Diciembre de 2001 junto con el autor, dentro de los Encuentros-coloquio sobre Amor, literatura y Psicoanálisis. 
340 Notas sobre psicoanálisis, literatura y comunicación. Algunas consideraciones

a propósito del amor en la novela Cuaderno de viaje de Salvador Compán

Algunos paralelismos entre Literatura y Psicoanálisis.

partir de la lectura de la novela Cuaderno de viaje de Salvador
Compán, trataremos de establecer una serie de relaciones que servirán
de punto de apoyo para unas reflexiones sobre la función del amor en
el proceso de comunicación.

Esta lectura en ningún momento pretende ser crítica psicoanalítica de la obra, más bien y por el contrario, a partir de la narración literaria, la descripción de personajes y escenas y el consiguiente goce de la propia experiencia de la lectura, trata de obtener las enseñanzas que el psicoanálisis pudiera recibir.

Entre estas dos disciplinas encontramos una serie de paralelismos; de ellos vamos a señalar algunos que nos van a servir como punto de partida para el desarrollo de ciertas reflexiones en torno al vínculo afectivo, esto es, en torno a la tríada amor, odio e ignorancia, que subyace a toda relación comunicativa.

El oficio de escritor y el de psicoanalista están atravesados por analogías que hacen que sus campos, a pesar de ser diversos en cuanto a su finalidad, encuentren amplias zonas de convergencia.

1. Tanto para el escritor como para el psicoanalista el discurso es el material elemental sobre el que trabajan ${ }^{2,3}$. La palabra, con su potencial polisémico y su carácter ambiguo, halla en la literatura una función estética que en el psicoanálisis se transforma en fin terapéutico ${ }^{4}$. Ambas disciplinas valoran especialmente la musicalidad, la similcadencia, el aspecto significante de la palabra además del semántico.

2. En muchas ocasiones la lectura presta palabras a la peor de las angustias, la angustia inarticulable que no posee palabras para su elaboración, la que se padece en silencio, produciéndose un efecto liberador al descubrir en los personajes conflictos semejantes a los propios, que, con la ayuda de la escritura literaria, facilita el desvelamiento, toma de conocimiento, replanteamiento y búsqueda de soluciones de aquellos nudos generadores de conflictos intrapsíquicos.

3. Para la formación del psicoanalista Freud recomendaba, además de la Filosofía, la Psicología y la Psiquiatría, el estudio y la profundización en discipli-

2 FREUD, S. Sobre psicoterapia (tratamiento por el espíritu). 1905. Obras Completas Ed. Amorrortu Buenos Aires, 1986 Vol 7, p.243.

3 LACAN, J. Función y campo de la palabra y del lenguaje en psicoanálisis en Escritos 1. Ed. S.XXI, México, 1984 p. 227.

4 A su vez hallamos esta imbricación entre literatura, arte y psicoanálisis en el valor terapéutico del arte y la literatura en sí y por sí mismos, en los efectos de identificación, abreacción, catarsis que se manifiestan en la lectura o en cualquier otra forma de contemplación de la obra de arte. 
nas tan aparentemente ajenas al médico y con los que no suele tropezar en su actividad profesional: Historia de la civilización, Mitología, Psicología de las religiones y Literatura ${ }^{5}$.

Difícilmente podemos encontrar textos tan certeros y agudos a la hora de penetrar en lo más profundo del ser humano como las obras de Cervantes, Shakespeare, Gracián, Flaubert... No tememos desvariar lo más mínimo al afirmar que la mejor psicopatología fenomenológica, la mejor clínica descriptiva la podemos encontrar en la mejor literatura.

4. En su encuentro con otros saberes -Matemáticas, Lingüística, Medicina, Psicología, Biología...- la teoría psicoanalítica siempre ha salido fortalecida en su vertiente científica. De su interlocución con el arte y la literatura, el psicoanálisis como disciplina apegada a la práctica, se puede beneficiar, ante todo, de la sensibilidad y el saber hacer del artista ante lo Otro, lo desconocido, lo diferente, lo que está de la parte de allá, todo aquello que habitualmente escapa a la percepción y el discurso común.

En este sentido nos interesa la mirada del novelista como receptor que aporta Otra percepción, otra perspectiva que va más allá de cualquier esquema, ya sea teórico o ideológico.

La escucha del analista permite poner de relieve algo en el discurso que resulta ajeno al propio sujeto emisor del enunciado, permitiendo una interlocución con lo Otro.

Y no es de extrañar, porque el oficio de escritor, de artista en general, exige una capacidad de percepción, la posesión y el dominio de un sexto sentido que permita percibir lo Otro, aquello que es menos fácilmente registrable. Por otro lado, estas antenas reclaman un trabajo continuo de afinación de esa sensibilidad para captar el mundo además de la elaboración de un universo propio que exige un cuerpo teórico, una estructura en la que integrar y dar sentido y alcance a las percepciones que esas antenas captan.

Este instrumento de percepción, desde el campo del psicoanálisis podemos decir que está íntimamente relacionado con el inconsciente. Estas antenas a las que nos referimos serán más sutiles y agudas en la medida en que se vean menos sometidas a los velos de la represión y más libres, por tanto, de la censura del inconsciente ${ }^{6}$.

5 FREUD, S. Psicoanálisis profano (Psicoanálisis y medicina). ¿Pueden los legos ejercer el análisis?.1926. Obras Completas. Ed. Amorrortu Buenos Aires, 1986. Vol 20, p. 165

6 FREUD. S. Interpretación de los Sueños. 1900. Obras Completas Ed. Amorrortu Buenos Aires, 1986 Vol 4 y 5 . 
342 Notas sobre psicoanálisis, literatura y comunicación. Algunas consideraciones

a propósito del amor en la novela Cuaderno de viaje de Salvador Compán

5. Los novelistas suelen hablar de cómo los personajes crecen por sí solos y dictan el destino de la narración. De forma parecida el psicoanálisis toma su rumbo a partir de la demanda del paciente. La puesta en palabras del sufrimiento trágico del ser humano es lo que dicta la dirección del trabajo terapéutico, si bien no de manera mecánica sino como resultado de una labor de interpretación.

Tanto en el caso del novelista, como en el del psicoanalista, podemos decir que los sujetos -ya sean personajes de una novela o pacientes en psicoterapiamarcan la dirección a seguir y que tanto el novelista como el analista deben ceñirse a seguir, observar, analizar, lo que esos personajes producen por sí mismos.

6. Un nueva coincidencia entre literatura y psicoanálisis la encontramos en la primacía de la forma sobre el contenido. En el escritor no se trata tanto de decir un argumento nuevo -ya están todos contados- como el estilo en que se cuenta. El estilo es el hombre. El estilo es la agudeza, el estilete, el instrumento que permite al autor penetrar en la naturaleza humana.

Lo esencial para el escritor no es el tema sino el estilo. Tal y como nos recuerda Borges continuamente, a estas alturas en que ya todo argumento está contado, es fundamental esa mirada subjetiva que enriquece lo que nos dice con su estilo.

Lo encontramos en el propio texto de la novela y parece escrito por un psicoanalista refiriéndose a su propia práctica.

«Más que lo que contaba, me interesó el modo de contarlo porque uno se acostumbra a ir haciéndose un rastreador de huellas de las personas que le importan, estudia sus actitudes, sus mínimos gestos, detalles de su vestido o de su vivienda: toda esa información que nos transmiten involuntariamente y que, a causa de ello, tiene el valor de lo auténtico»?

\section{En torno a la forma}

1. En relación con la forma en esta novela de Salvador Compán, Juan García, el novelista dentro de la novela, trabaja su documentación a la manera en que lo hace el psicoanalista con el material del paciente. Éste, por una parte escucha el discurso "oficial", el contenido manifiesto, el enunciado que el paciente va desplegando, pero para el analista es fundamental cualquiera de los agujeros en ese discurso -lapsus, olvido, error en la sintaxis o en la lógica del discurso...que

7 COMPÁN, S. Cuaderno de viaje. Ed. Planeta. Barcelona, 2000. p.184. 
conforman el cuaderno de viaje/vida del paciente- donde el inconsciente va dejándose emerger ${ }^{8}$.

Juan García, elabora su novela recopilando percepciones, sensaciones, ideas, datos, conversaciones, que van quedando reflejadas en el Cuaderno de viaje bajo la forma de notas, dibujos, observaciones, impresiones que la investigación de los hechos le van proporcionando; un material aún no sometido a corrección, de donde posteriormente, y por selección de acuerdo con los criterios dictados por Cándido Espejo, se extraerá la novela oficial.

La novela que leemos es en sí el conjunto de ideas latentes que la censura dejó fuera de esa novela oficial ${ }^{9}$ - que sería la que encarga Cándido Espejo, la que no leemos-.

2. Por otra parte Cándido Espejo encarga a Juan García una historia que magnifique los aspectos más brillantes de la historia de la familia eliminando todo aquello que oscurezca el buen nombre y la dignidad del linaje de los Seisdedos, con objeto de crear una versión oficial, abiertamente hagiográfica.

Esta estrategia no deja de evocar lo que en psicoanálisis se conoce como novela familiar, es decir aquellas fantasías en las que el sujeto suele imaginarse como hijo de unos padres imaginarios magníficos, dotados de todos los atributos de excelencia, con que trata de compensar las carencias generadas al descubrir ciertas faltas en sus padres que los alejan del rango de omnipotencia con que hasta entonces los había investido; fantasías, al cabo, con que el niño trata de dar respuesta a los enigmas sobre el origen.

3. A través del recurso de la investigación llevada a cabo por Juan García para la elaboración del material de su novela observamos cómo el tratamiento de las situaciones, se va construyendo/desconstruyendo desde los diferentes vértices o elementos que conforman la estructura de cada escena, de una forma que evoca el trabajo que realiza el psicoanalista con las fantasías -atravesamiento- y los sueños -análisis-. La historia en la novela se va construyendo/desconstruyendo desde las versiones de Cándido Espejo, el Padre Expósito y Margarita, el diario de Rafael, etc, vértices todos ellos que prestan una perspectiva diferente a la construcción de las situaciones.

8 LACAN, J. Comentario hablado sobre la Verneinung de Freud por Jean Hippolite, Escritos Ed. S.XXI, México, 1984, t. 2, p.859.

9 Que podríamos, en léxico psicoanalítico de la Interpretación de los sueños, denominar elaboración secundaria. 
344 Notas sobre psicoanálisis, literatura y comunicación. Algunas consideraciones

a propósito del amor en la novela Cuaderno de viaje de Salvador Compán

4. Si nos aproximamos a la novela con la pregunta de R. Jacobson ${ }^{10}$ ¿qué es lo que hace que esta novela pueda ser considerada una obra de arte?, podríamos respondernos, con Lacan que partiendo de un tratamiento metonímico, la novela se hace metáfora ${ }^{11}$.

Partiendo de un texto fragmentario -así lo encontramos, por ejemplo en las diferentes versiones subjetivas y parciales recogidas por Juan García- la novela se nos representa como una metáfora ${ }^{12}$ generadora de sentidos y significaciones inagotables ${ }^{13}$. La narración, tejida como novela-metonimia resulta en su producto novela-metáfora.

En esta novela se nos narra la genealogía -origen, evolución, destino...- de una familia, unos personajes, una sociedad, un momento histórico, se nos presenta una descripción de la naturaleza humana y sus pasiones más elementales, del orden social...o si se quiere hasta el origen de la generación del latifundio alegoría a su vez del origen del capital.

Volviendo a la cuestión del estilo, la forma en que lo hace invita a una lectura fecunda, propicia una labor de pensamiento que engendra evocaciones, invita a reflexiones que generarán nuevos sentidos y significaciones -sustitución significante al fin, propia del eje metafórico-.

\section{En torno al contenido}

En relación con el contenido encontramos en esta novela una reflexión sobre las formas más elementales de la naturaleza y las pasiones humanas.

Tal y como se plasma en el texto, podríamos distinguir una primera parte, dedicada casi exclusivamente a las pasiones agresivas, destructivas, aquellas que bien podríamos hacer corresponder con las pulsiones de agresivo-destructivas ${ }^{14}$.

Pasiones destructivas como codicia, avaricia, ambición, odio conforman la materia pasional con que se elabora esta primera parte de la novela en que se narra cómo levantan los Saturios su patrimonio a través del ejercicio del dominio y del poder sobre sus víctimas, generando un fortuna erigida a base de expolio, extorsión, bandidaje y crueldad.

Esta voluntad de dominio va a dar como resultado una relación amo-esclavo que contiene el germen de la propia resolución del relato. El amo necesita el

10 JACOBSON, R. Lingüística y poética, en Ensayos de Lingüísticas General, 1985 Ed. Planeta-Agostini p. 348

11 LACAN, J. La instancia de la letra. Escritos 1. Ed. S.XXI, México, 1984 p.486 y 487

12 LACAN, J. Seminario 5. 1957-58. Ed. Piadós, 19

13 El propio autor en una comunicación personal en el marco de los Encuentros-coloquio nos confió que su posición como novelista es la de generar una metáfora.

14 Relacionables con las pulsiones del yo en la primera teoría pulsional freudiana o bien con las pulsiones de muerte en la segunda teoría pulsional. FREUD, S. Las dos clase de pulsiones en 1923, El yo y el Ello.. Obras Completas. Ed Amorrortu, Buenos Aires, 1986 t. XIX., p. 1. 
reconocimiento del siervo/víctima, pero en este sometimiento se vislumbra la acumulación de tensión agresiva de las víctimas, necesaria para que, con el tiempo, se genere el movimiento de venganza, -deseo de muerte del amo- que viene a cumplirse como un rito- y que sigue la mecánica del retorno de lo reprimido ${ }^{15}$.

En esta novela se nos describen dos tipos de ejercicio del poder claramente diferenciables, aquel que ejercen los Saturios de forma brutal y grosera y la otra más racional, ilustrada de Rafael Seisdedos, quien a pesar de sus escrúpulos y sus esfuerzos más o menos esnobistas de distanciarse de sus antecesores en la relación sanguinaria hacia el otro, no declina esa voluntad de dominio que parece marcar a los Seisdedos con un estigma familiar.

En Rafael Seisdedos la voluntad de dominio se ejerce de una forma más sutil, con una aspiración de convencimiento del otro a través del raciocinio.

Dentro de estos primeros capítulos dedicados a las pasiones destructivas, encontramos unas historias que tienen un lugar relevante en la tradición de la literatura castellana, los odios cainitas.

Una de ellas es la relación del padre Expósito con Rafael Seisdedos. El padre Expósito, heredero del más genuino espíritu saturio, bárbaro y brutal, vive bajo el estigma del hijo bastardo que comienza reivindicando la demanda justa de un lugar en la familia y termina rapiñando lo que considera su parte del patrimonio a base de la extorsión y el chantaje afectivo.

Otra de estas parejas cainitas la hallamos en la relación de Cándido Espejo con su cuñado Rafael Seisdedos, relación que puede recordarnos a Salieri y Mozart.

Ante el silencio pleno del que Rafael Seisdedos se siente dueño, Cándido Espejo es esclavo del vacío de sus palabras en una fascinación que lo colocará en actitud servil ante Rafael Seisdedos.

La idealización con que Cándido admira a Rafael le coloca en un lugar de sumisión en el que la acumulación de envidias y hostilidades se transformará en venganza en cuanto las circunstancias lo permitan, delatando a su cuñado, intrigando contra éste ante Nieves la matriarca o confabulando contra él en nombre de la moral y la decencia cuando éste introduce, en una maniobra desesperada, a Ana Bárcena -una prostituta- en la casa familiar.

En la narración asistimos a una admirable contraposición de dos formas de la misma pasión ${ }^{16}$, el odio franco, primario del padre Expósito y el odio insidioso de Cándido Espejo.

15 FREUD. 1896, Nuevas puntualizaciones sobre las neuropsicosis de defensa. Obras Completas Ed. Amorrortu Buenos Aires, 1986, t .III. p.157.

16 GURMENDEZ, C. Tratado de las pasiones. Ed. Fondo de Cultura Económica, Madrid. 1997. 
346 Notas sobre psicoanálisis, literatura y comunicación. Algunas consideraciones

a propósito del amor en la novela Cuaderno de viaje de Salvador Compán

Pero es en la segunda mitad de la novela, la dedicada más claramente a la relación de Rafael Seisdedos y Ana Bárcena, donde el estilete del novelista penetra con más perspicacia y sutileza en los entresijos de la pasión. Donde, gracias al recurso del diario de Rafael, se interna con más determinación en una escritura intimista del desgarro sufrido por un hombre que se entrega -y no renuncia a su pesar- al desafío del deseo hasta las últimas consecuencias.

Es en esta parte donde la lectura se va remansando en la medida en que los personajes, sobre todo Rafael, van tomando un rumbo más complicado, ajeno a esquemas, cercano a la verdad pulsional.

La novela presenta un cierto desequilibrio. El lector, atrapado en la pasión de Rafael, desea que la narración se dilate ${ }^{17}$; no obstante, esta merma queda compensada con un lenguaje poético e intenso, en el que la descripción se hace más evocadora y donde cada párrafo está cargado de una enjundia propia la mirada de un novelista.

Las historias de amor descritas en la novela representan un muestrario de diferentes formas del encuentro erótico. Por una parte se nos muestran las extrañas relaciones de los Saturios y sus mujeres. Éstos parecen condenados a la condición erótica de disociar ternura y sensualidad ${ }^{18}$. Como objeto de elección la mujer debe quedar bien disociada. Aquella que será objeto de ternura, la madre legítima de los hijos reconocidos, es idealizada como madre virginal. En cambio, Maribaila ocupará el lugar de la mujer objeto de sensualidad. Disociación descrita por Freud y atribuida especialmente a seres especialmente primitivos o bien cargados por determinados aspectos perversos.

Respecto a las formas de comportamiento erótico y en especial a estas menciones freudianas, habría que referirse al carácter peculiar que parece ser común denominador de los objetos eróticos de Juan García. Tanto en la relación amorosa con una mujer casada que deja en Madrid como sus escarceos con la esposa de Esteban Molina el arriero, o su relación con Lucía Lara, encontramos un elemento común, las tres tienen pareja. Hallamos aquí una alusión a la indicación freudiana referente a una condición en la elección de objeto en ciertos hombres: la necesidad de un tercero para avivar el deseo hacia un objeto de elección.

Vamos a mencionar sin detenernos, aunque bien podría requerir mayor atención, la pareja formada por Cándido espejo y Margarita, o la de aquél y su primeras novia de Madrid, o la del Padre Expósito y su amancebada Rosa, historias apenas esbozadas donde se da cuenta de la complicada estructura del eros

17 A este comentario, el autor respondió que esta segunda parte, que era en un principio bastante más extensa, sufrió un recorte severo bajo el criterio de hacer una lectura más aliviada.

18 FREUD, S. Contribuciones a la psicología del amor. Obras Completas Ed. Amorrortu Buenos Aires, 1986, t XI. 
-sus relaciones con el apego, las urgencias pulsionales, los intereses sociales, la necesidad biológica, la complejidad de los sentimientos, la sensualidad, el afecto...-.

En cambio vamos a detenernos en la historia pasional de Rafael Seisdedos. Este personaje, que a lo largo de la primera mitad de la novela aparece como un ser enigmático, marcado por un temple racional y dominador, se nos revela como arrebatado por los impulsos más primarios cuando, respondiendo a la llamada de la sangre, clama venganza de forma desaforada tras el asesinato de su padre y su abuelo. Ya en este pasaje, determinante en la estructura de la narración, se descubre cómo en los sótanos del sólido edificio que Rafael ha intentado construir a base de templanza, fuerza interior contenida y una férrea voluntad de dominio se encierra el desafuero saturnal. ( del que intenta escaparse durante toda su vida sin conseguirlo)

Aunque en el episodio de su relación con María Vico aparece como un personaje desapasionado, distante ante las convenciones, frío ante los sentimientos, regido por los intereses, posteriormente se nos va a ir mostrando como un personaje en busca de su destino.

En su cumpleaños, momento elegido para dar fin al duelo por la muerte de los Saturios, este hombre, que ha cimentado su dignidad en la asunción de emblemas sociales, queda poseído por un deseo, que se presenta más irrenunciable cuanto más imposible.

La atracción de Ana llega a obsesionarle hasta tal punto que buscará protección en la lectura, en la disciplina del trabajo o en la pintura.

Este hombre dominador, respetuoso con las convenciones sociales, romperá, llevándose a su casa a Ana Bárcena, enfrentándose a los reproches de su familia y a la vergüenza social llegando al extremo del desfalco.

Azuzada por las insidias de Cándido Espejo, la abuela Nieves resurge de entre los muertos y se erige en baluarte de la moral. El cerco se va cerrando en torno a la pareja, que cada día vive más en clausura su pasión. Rafael huye -con Ana- del asfixiante universo familiar con lo puesto, y se abisma a una espiral que lo llevará desde la complacencia en los emblemas de la prestancia social hasta el despojamiento de su identidad social ejerciendo como alcahuete de su amada.

Destino desgraciado -Ana lo abandona por un rentista-, de ruina, miseria y muerte, rasgos que definen el amor-pasión ${ }^{19}$. 
348 Notas sobre psicoanálisis, literatura y comunicación. Algunas consideraciones

a propósito del amor en la novela Cuaderno de viaje de Salvador Compán

\section{Algunos interrogantes para la discusión}

1. ¿Podríamos establecer una cierta relación entre la pasión amorosa de Rafael y acontecimientos anteriores?.

En la novela asistimos a la presentación de Rafael Seisdedos como un personaje dominador de sus impulsos, pero ante el asesinato de su padre $-\mathrm{y}$ su abuelo-, presa de un arrebato de ira y siguiendo la llamada de la sangre saldrá, clamando venganza. Al encuentro de Anselmo Feliú, este inocente halla la muerte en sus manos. Tras caer en un estado de melancolía -que aprovechará el padre Expósito para intrigar- y tras un tiempo de elaboración de ese sentimiento de culpa, durante el que pasa por un momento de locura transitoria -simbolizada en el loco Valor y su amistad con él-, buscará un castigo -que expíe el sentimiento de culpa- que encuentra en la pasión amorosa que finalmente le conducirá a la desgracia y la destrucción.

2. En relación con la pasión de Rafael Seisdedos, que roza el sexo, el misticismo y la destrucción, ¿podríamos decir que en su enamoramiento invierte la fórmula "amo lo que no deseo, deseo lo que no amo" 20 y que el objeto elegido sigue la vía de la unión en un objeto de lo sensual y lo afectivo? A diferencia, por ejemplo de los Saturios, quienes necesitan separar la mujer idealizada -Nieves, Adela- de la profanada -la Maribaila, que, no en vano se la llama precedida del artículo.

En Ana Bárcena se condensan las corrientes, afectiva y sensual, transformando la fórmula en «amo lo que deseo y gozo de lo prohibido».

Esta historia de amor es un intento frustrado de vencer la escisión impuesta por la Civilización, origen de un malestar malestar intrínseco a la estructura social.

3. Paradoja eros-muerte. Podríamos aventurar que tanto Rafael Seisdedos como los Saturios encuentran la muerte en el lugar del placer, casas de lenocinio.

Éstos son sorprendidos por la muerte en la casa de la Maribaila. Rafael morirá en la casa que se supone compartía con Ana, donde él ejerció de proxeneta. Encuentra la muerte en el lugar del amor.

En los hombres de la familia Seisdedos el ímpetu de la conquista se convierte en torpeza y desacierto a la hora del amor.

Dominadores en las pasiones agresivas, los Seisdedos se convierten en dominados en el terreno de las pasiones eróticas.

20 FREUD, S. Contribuciones a la psicología del amor. Obras Completas Ed. Amorrortu Buenos Aires, 1986, tXI. 
4. El encargo de Cándido Espejo, cercano a su muerte, a Juan García plantea una cuestión existencial, qué hacer ante la evidencia de la muerte.

Quizá podríamos quedar estuporizados en la desesperación como consecuencia del shock narcisista disparado por la certeza de lo limitado de la vida.

O quizá rehacer el rumbo de la existencia aceptando el propio destino. En este caso se suele decir que la muerte ayuda a valorar la vida. Sólo se vive una vez, se suele objetar como justificación a estos golpes de timón.

O quizá inventar una vida, complaciéndonos en una ficción - ¿defensa narcisista ante la muerte?- que por lo general intenta suplir un pasado anodino. Este parece ser el caso de Cándido Espejo, quien, al final de su vida y al hacer balance de lo miserable de su existencia, encuentra consuelo en reinventarse en esa novelamáscara encargada a Juan García donde se repite la estrategia del ocultamiento y la mentira que marca su biografía.

5. El autor parece sensibilizado ante el peso del nombre propio en la estructura de un sujeto. Quizá por eso la elección de los nombres de los personajes parece translucir unas intenciones. Juan García Martínez nombre y apellidos convencionales para alguien que se plantea con su escritura dejar una marca. Saturios, Seisdedos que evocan la transgresión que representan. Expósito para el hijo natural que no es reconocido como hijo y es padre por una vía tan poco natural. El loco Valor necesitado por Rafael Seisdedos, Margarita...

Pero sobre todo llama la atención el nombre de Cándido Espejo -que bien refleja los aspectos más mezquinos de la condición humana-.Este personaje se nos presenta, de manera cándida, como un verdadero espejo que refleja la sordidez en aquellos que entran en la esfera de su influjo. Así en el principio de la novela, Juan García no puede dejar de sentirse un miserable al aceptar poner su escritura al servicio de la infamia por un puñado de reales.

6. En las reflexiones del escritor Juan García sobre la autenticidad contraponiendo novela-máscara versus novela-verdad ${ }^{21}$, se equipara realidad y verdad.

...Le hablé de la novela-verdad que pienso escribir, tal como se hace hoy en Francia, un nuevo modo narrativo que calca hechos y personajes, y concibe al autor a la manera de una mano que arranca un trozo de realidad y ciñe sobre él las palabras como si éstas fueran la cera con la cual hacen los escultores sus duplicados.

Pero, ¿podríamos diferenciar realidad y verdad como lo hace el psicoanálisis?. En la psicoterapia psicoanalítica se distingue entre buscar el origen del síntoma en un acontecimiento acaecido en la realidad y buscar el origen del

21 COMPÁN, S. Cuaderno de viaje. Ed. Planeta. Barcelona, 2000, p.165-6-7 y p. 173. 
350 Notas sobre psicoanálisis, literatura y comunicación. Algunas consideraciones

a propósito del amor en la novela Cuaderno de viaje de Salvador Compán

conflicto en la verdad del deseo tal y como se pone en juego en la fantasía -teoría fantasmática-. ¿Podríamos diferenciar realidad entendida en un sentido fenoménico propio del materialismo mecanicista de la teoría traumática y verdad tomada en un sentido nouménico que apunta a la congruencia interna del discurso?.

(Recibido el 18-12-2001, aceptado el 24-1-2002) 